Business \& Entrepreneurship Journal, Vol. 9, No. 1, 2020, 1-28

ISSN: 2241-3022 (print version), 2241-312X (online)

https://doi.org/10.47260/bej/911

Scientific Press International Limited

\title{
The Analysis of Blocking Behavior and Pricing: The Case of Airbnb
}

\author{
Yifeng Peng ${ }^{1}$
}

\begin{abstract}
Over the years, as people's lives have improved, our need for transportation and accommodation has increased, driving the rapid growth of the sharing economy. Some well-known network sharing platforms, such as Uber, Drip and Airbnb, provide a large number of convenient options for users with transactional needs, make more use of idle tourism, accommodation and other resources. Sharing economy platforms continue to improve the content and format of their products, but at the same time, the future of sharing platforms and the difficulty of competition is a concern as more platform companies become involved and prices become more transparent. Under this circumstance, optimizing product pricing has become an urgent need for many sharing economy platforms. In this paper, we take Airbnb as the starting point and conduct an empirical analysis of the blocking behavior of homeowners based on proprietary data to explore the factors that affect their product supply. We find that price, number of beds, and listing type all have a significant impact on blocking houses. After that, we conducted further research on price factors and developed a model aiming at profit maximization to obtain the best pricing range for the region and provide suggestions for pricing strategies.
\end{abstract}

Keywords: Sharing Economy, Blocking behavior, Pricing Strategy, Airbnb

${ }^{1}$ School of Economics and Management, Southeast University.

Article Info: Received: October 15, 2020. Revised: October 31, 2020.

Published online: November 2, 2020. 


\section{Introduction}

With the emergence of peer-to-peer platforms, collectively known as the "sharing economy", has enabled individuals to collaboratively make use of under-utilized inventory via fee-based sharing. Examples include Turo, Uber and Airbnb. Sharing economy shakes the traditional industry in many ways. Ride-on-demand services (Uber, Didi) are driving the low-efficient taxi companies out of the market. Carsharing services (Turo, Zipcar) are threatening the traditional care rental businesses. Accommodation sharing services (Airbnb, HomeAway) compete with the hotels and drain their profits to individual home owners. Work space sharing services (ShareDesk, Netspace) largely reduce the expenses of starting up a firm. P2P lending services (LendingClub, OnDeck) are more convenient and have looser requirements than commercial bank products. Online trade platform (eBay, JD.com) eliminate the cost of market entry and reduce the goods delivery costs. On the other hand, sharing economy also faces some challenges such as regulatory risks, costs of consumer protection, reputation risk of platform.

In this paper, we look into some specific issues on the structure and operations of share economies and see how technology may help them address these issues. For example, the factors that influence the blocking or available behavior of landlord. We would also like to compare sharing economies with traditional economies, conduct utility analysis and find the best pricing range of the listing property. Provide help to reduce idle resources.

In this paper, we empirically investigate them on the popular online rental marketplace Airbnb.com. Since its founding in 2008, Airbnb has facilitated over two million room rentals, and investors valued Airbnb at roughly $\$ 2.5$ billion as of October 2012. Transactions on Airbnb are inherently risky-arranging short-term tenants for rooms in apartments and houses, or even entire dwellings. In order to investigate blocking behavior and utility, we obtained data from Airbnb officials. We combined the daily price of houses in April 2015 and various attributes to construct a data set to conduct empirical analysis of blocking behavior based on proprietary data for property owners.

We rely on market factor models to study the empirical properties of sharing economy. We also rely on structural or reduced-form econometrics to estimate the impact of operational factors. The utility framework will also be introduced to handle the platform resource allocation problem. In the end, we get the influence of price and property type factors on the product supply side, and research an optimal pricing range.

\section{Operation Mechanism of Airbnb}

The behavioral connotation of Airbnb platform operation includes Airbnb official, supplier and consumer. His operating mechanism first obtains an account on the Airbnb platform. The people who need to obtain the account are the customers of both parties, that is, individual vendors (landlords) who provide products or services and some consumers (tenants) who need to trade. Renters can open the APP, enter 
filter conditions, sort by a certain attribute, or directly search from the APP map to match their favorite rooms and other services (various activities). The platform matches buyers and sellers through algorithm recommendation, interface display, key docking, etc. If different currencies are used, a 3\% currency exchange fee will also be charged; The platform will first collect transaction fees from both parties, and then this deducted part of the funds will be transferred to the bank card bound by the landlord, and the whole process will be over. Throughout the process, the information and privacy of customers on both sides of the transaction are protected by the platform. Finally, both parties of the transaction realize information feedback by evaluating each other. In the event of a dispute, the platform also needs to provide services such as arbitration and legal consultation, problem solving, compensation or setting a party's compensation.

\section{Related Work}

The "sharing economy" is a burgeoning business model in which people offer their personal belongings and personal services to others, usually through online marketplaces that facilitate the transactions.

It seems absolutely egalitarian at face value: Anyone who owns a sometimes-unused thing-an apartment, a car, a boat-now has an easy way to advertise and share it. And anyone with the time and skills-driving, running errands-can find customers who need these services. But new research shows how online marketplaces can work in ways that are anything but egalitarian:

They can inadvertently fuel racial discrimination.

In Digital Discrimination: The Case of Airbnb.com (Edelman, Luca and Michael, 2014), the authors investigate the possibility of racial discrimination against people who advertise properties on Airbnb, a popular online marketplace that lists temporary rooms and homes in some 34,000 cities across 192 countries.

Edelman and Luca construct a data set combining pictures of all New York City landlords on Airbnb with their rental prices and information about characteristics and quality of their properties, using this data to measure differences in outcomes according to landlord race and find that:

First, online marketplaces have the potential to reduce discrimination by facilitating more arms-length transactions. However, social platforms such as Airbnb.com, a popular online marketplace for short-term rentals, may have the opposite effect.

Second, this paper investigates the differences in prices of properties from landlords of varying races. Non-black landlords charge approximately $12 \%$ more than black landlords for comparable properties.

Third, online marketplaces should think carefully about whether, and why, the looks of buyers and sellers should be relevant to the purchase at hand.

Fourth, Airbnb might consider eliminating or reducing the prominence of landlord photos. It is not clear what beneficial information these photos provide, while they risk facilitating discrimination by guests.

For starters, Luca and Edelman suggest evaluating whether profile pictures provide 
any necessary information to the customer. "For instance, ask yourself what useful information you learn from looking at the Airbnb landlord's face," Edelman says. "The last time I was an Airbnb guest, I never laid eyes on the landlord except on the website. There was a neighbor facilitator who dropped off the keys and picked them up." In any case, the researchers recommend putting profile pictures in a less prominent place, perhaps on a separate page from the picture of the product or property. (On Airbnb, the landlord's profile picture is the second-most prominent element on any listing page, displayed next to the default picture of the property). "Research has shown that when something is more salient, you respond more to it," Luca says. "This is something a platform should think about in its design decisions. Is a landlord's physical appearance really the information Airbnb most wants to emphasize?"

More generally, the researchers recommend that sharing-economy companies take website design seriously and to question early on whether their system design encourages racial bias. "These questions are too important to be left to engineers, and too important to be left to graphic designers", Edelman says.

As they continue this line of research, Edelman and Luca are studying some of the online ride-sharing services of the sharing economy. Such services are especially relevant to racial bias studies, they explain. Booking a cab online has the potential to eliminate the possibility that a driver will decline to pick up a black person who is hailing a cab. But racial bias will still be a problem if the customer is required to provide a profile picture when signing up for the service." In so many contexts, online information systems can be much better than the real-world alternatives than they replace, "Edelman says. "But they can also be much worse. The burden is on us, as system designers, to get it right".

To investigate whether peer-to-peer rental markets for durable goods are welfareimproving, in Peer-to-Peer Rental Markets in the Sharing Economy (Fraiberger and Sundararajan, 2017), the authors develop a new dynamic model of such markets in which users with heterogeneous utilization rates may also trade in secondary markets. The authors discuss three distinct studies they have worked on.

The first study presents a new dynamic model of peer-to-peer Internet-enabled rental markets for durable goods in which consumers may also trade their durable assets in (traditional) secondary markets, transaction costs and depreciation rates may vary with usage intensity, and consumers are heterogeneous in their price sensitivity and asset utilization rates. The study characterizes the stationary equilibrium of the model. It analyzes the welfare and distributional effects of introducing these rental markets by calibrating the model with US automobile industry data and 2 years of transaction-level data obtained from Getaround, a large peer-to-peer car rental marketplace. Counterfactual analyses vary marketplace access levels and matching frictions, showing that peer-to-peer rental markets change the allocation of goods significantly, substituting rental for ownership and lowering used-good prices while increasing consumer surplus. Consumption shifts are significantly more pronounced for below-median income users, who also provide a majority of rental supply. Their results also suggest that these below- 
median income consumers will enjoy a disproportionate fraction of eventual welfare gains from this kind of 'sharing economy' through broader inclusion, higher quality rental-based consumption, and new ownership facilitated by rental supply revenues. The second study analyzes over 178,000 five-factor personality profiles of users of an online reputation provider and their Facebook social network. It provides evidence of friendship based on similarities in personality traits, shows how personality similarity is related to network embeddedness, and suggests a model of tie formation based on matching opportunities created by shared friends. The final study uses a dataset of over 536,000 news articles from Reuters about 16 countries over the period 1988 to 2013. It constructs a sentiment measure using the fraction of positive and negative words in the text, and demonstrates that this measure can improve predictions of macroeconomic and financial variables. This measure also improves the forecast of the economy compared to the consensus forecast, and supports a model where forecasters do properly incorporate all the available information in forming their expectations.

The Internet has greatly reduced entry and advertising costs across a variety of industries. Peer-to-peer marketplaces such as Airbnb, Uber, and Etsy currently provide a platform for small and part-time peer providers to sell their goods and services. In the paper The Welfare Effects of Peer Entry in the Accommodation Market: The Case of Airbnb (Farronato and Fradkin, 2018), the authors study the determinants and effects of peer production in the market for short-term accommodation, where Airbnb is the main peer-to-peer platform and hotels are incumbent suppliers.

Since its founding in 2008, Airbnb has grown to list more rooms than any hotel group in the world. Yet Airbnb's growth across cities and over time has been highly heterogeneous, with supply shares ranging from over 15 percent to less than 1 percent across major US cities at the end of 2014. Airbnb's entry has also prompted policy discussion and varied regulation in many cities across the world. In order to understand Airbnb's growth and its effects, Farronato and Fradkin propose a simple demand and supply framework where accommodations can be provided by either dedicated or flexible supply-hotels vs peer landlords. They then use data from top US cities to test the model hypotheses about the entry of peer supply, and to quantify the effects of this entry on travelers, incumbent hotels, and peer landlords. They find that Airbnb generated $\$ 41$ of consumer surplus per room-night and $\$ 26$ of landlord surplus while reducing variable hotel profits from accommodations by up to 3.7 percent. This resulted in a total welfare gain of $\$ 137$ million in 2014 from Airbnb in these cities and this effect was concentrated in locations (New York) and times (New Year's Eve) where hotel capacity was constrained.

This paper informs the active policy debate regarding whether and how to regulate peer-to-peer accommodations. The result favors a regulatory framework that preserves the benefits of peer production during peak demand days while achieving a broader set of objectives such as consumer protection, affordable housing and fair competition.

In The Rise of the Sharing Economy: Estimating the Impact of Airbnb on the Hotel 
Industry (Zervas, Proserpio and Byers, 2016), the authors explore the economic impact of the sharing economy on incumbent firms by studying the case of Airbnb, a prominent platform for short-term accommodations. They analyze Airbnb's entry into the state of Texas and quantify its impact on the Texas hotel industry over the subsequent decade, using a dataset collected spanning all Airbnb listings in Texas and a decade-long panel of quarterly tax revenue for all Texas hotels, they develop a nuanced estimate of Airbnb's material impact on hotel revenues. Their baseline estimate is that a $1 \%$ increase in Airbnb listings in Texas results in a $0.05 \%$ decrease in quarterly hotel revenues, an estimate compounded by Airbnb's rapid growth. To further isolate Airbnb's impact, they employ hotel segments that consumers are less likely to substitute for Airbnb stays as additional control groups and find that the impacts are distributed unevenly across the industry, with lower-end hotels and hotels not catering to business travelers being the most affected. Finally, by simulating various regulatory interventions informed by current events, such as limiting Airbnb landlords to a single listing, they find only a moderate mitigating impact on hotel revenues.

In the analysis, the authors believe that the economic costs Airbnb imposes likely outweigh the benefits. While the introduction and expansion of Airbnb into U.S. cities and cities around the world carries large potential economic benefits and costs, the costs to renters and local jurisdictions likely exceed the benefits to travelers and property owners. The potential benefit of increased tourism supporting city economies is much smaller than commonly advertised. There is little evidence that cities with an increasing supply of short-term Airbnb rental accommodations are seeing a large increase in travelers. Instead, accommodations supplied via Airbnb seem to be a nearly pure substitution for other forms of accommodation. Two surveys indicate that only 2 to 4 percent of those using Airbnb say that they would not have taken the trip were Airbnb rentals unavailable.

Studies claiming that Airbnb is supporting a lot of economic activity often vastly overstate the effect because they fail to account for the fact that much of this spending would have been done anyway by travelers staying in hotels or other alternative accommodations absent the Airbnb option.

The shift from traditional hotels to Airbnb lodging leads to less-reliable tax payments to cities. Several large American cities with a large Airbnb presence rely heavily on lodging taxes. Airbnb has largely blocked the ability of these cities to transparently collect lodging taxes on Airbnb rentals that are equivalent to lodging taxes on hotel rooms. One study found that the voluntary agreements Airbnb has struck with state and local governments "[undermine] tax fairness, transparency, and the rule of law."

City residents likely suffer when Airbnb circumvents zoning laws that ban lodging businesses from residential neighborhoods. The status quo of zoning regulations in cities reflects a broad presumption that short-term travelers likely impose greater externalities on long-term residents than do other long-term residents. Externalities are economic costs that are borne by people not directly engaged in a transaction. In the case of neighbors on a street with short-term renters, externalities include 
noise and stress on neighborhood infrastructure like trash pickup. These externalities are why hotels are clustered away from residential areas. Many Airbnb rental units are in violation of local zoning regulations, and there is the strong possibility that these units are indeed imposing large costs on neighbors.

Because Airbnb is clearly a business competing with hotel lodging, it should be subject to the same taxation regime as hotels. In regard to zoning regulations, there is no empirical evidence that the net benefits of Airbnb introduction and expansion are so large that policymakers should reverse long-standing regulatory decisions simply to accommodate the rise of a single company.

In the article The Value of Flexible Work: Evidence from Uber Drivers (Chen, Judith, Peter E. and Emily, 2018), the authors collected data over an eight-month period and found that Uber driver arrangements attract more than a million drivers to provide labor supply. Not only do drivers have the option of offering a relatively small number of hours per week, but they also have the flexibility to allocate those hours over several days and hours of the week. However, this is not the only or even the most important source of flexibility offered to Uber drivers. Another important source of flexibility is the ability of Uber drivers to adapt to changes in time demands on an hourly basis. While traditional workplaces compete in providing flexibility to their employees, the literature suggests that low-wage, low-skilled employees are often limited in their ability to cope with daily shocks. The goal of this thesis is to propose a model of labor supply to allow for the quantification of the value of flexibility and adaptability.

The authors assume a model in which each driver has a wage retention process that has a predictable average component as well as weekly, daily, and hourly shocks. This exposes workers to unpredictable events that can alter their hourly labor supply decisions. The authors assume that drivers form rational expectations about expected wages and make labor supply decisions on an hourly basis by comparing their reservation wage to their current expected wage. The model is a multivariate Probit model with time-varying truncation points and is easier to identify than the traditional Probit structure. Drive-level accurate finite sample inference can be achieved using a hybrid MCMC approach.

Their analysis shows very large shock differences, suggesting that in an Uber-like arrangement, there may be a large surplus of drivers, leaving drivers to decide when to work on an hourly basis. Based on existing arrangements and other work arrangements, the authors calculate driver surplus labor (40 percent of expected gross earnings, or an average of $\$ 150$ per week), which limits the ability of drivers to adapt to hourly and daily booking wage shocks. Limits on the ability to adapt to shocks have a significant impact on the expected labor surplus, and eliminating this ability would reduce the surplus labor by more than two-thirds. The authors also consider a taxi-style arrangement in which drivers can decide each day whether to work and which of three shifts to work, but must work the entire eight-hour shift. The taxi arrangement reduces the expected surplus labor force to one-eighth of the Uber arrangement.

In summary, the literature documents an important source of value in flexible work 
arrangements, the ability to adjust work schedules to deal with unpredictable reserve shocks, and this adaptability is of high value to individuals who choose to join the Uber platform. The authors' expectation is that technology will drive the growth of more Uber-style work arrangements. While such arrangements may have important drawbacks relative to the traditional occupations they replace, the authors expect flexibility to be an important source of value in such arrangements.

It can be seen that most of the research directions of the sharing economy focus on the exploration of the demand side, and they are more willing to study the advantages and utility of the sharing economy relative to the traditional economy. Although there is a research on the work arrangement of drivers in the paper on Uber, it mainly focuses on the flexible work arrangement system. There is a lack of research on the supply-side behavior of shared leasing platforms and short-term empirical analysis using proprietary data. These shortcomings are also the starting point of this article. This article conducts an empirical analysis on the blockade behavior of listed property owners based on proprietary data, understands the impact of changes and gives corresponding pricing strategies.

\section{Correlation Study}

\subsection{Data}

We obtained data from the AirDNA website (https://www.airdna.co) and used property data for an area of New York (Concentrated in the East Village. Figure 1) during April 2015.

We removed transactions from the original data that had booking dates and checkin dates more than one month and used the remaining data for regression analysis. Because some apartments allow customers to book several months or more in advance, but they charge more because of the risk premium.

Table 1: Descriptive Statistics of Variables I

\begin{tabular}{|c|c|c|c|c|}
\hline Variable & Mean & $\begin{array}{c}\text { Standard } \\
\text { Deviation }\end{array}$ & Max & Min \\
\hline Price & 181.27 & 137.31 & 2500.00 & 40.00 \\
\hline Bedrooms & 1.09 & 0.71 & 7.00 & 0.00 \\
\hline Occupancy Rate & 0.619 & 0.252 & 1.000 & 0.033 \\
\hline
\end{tabular}




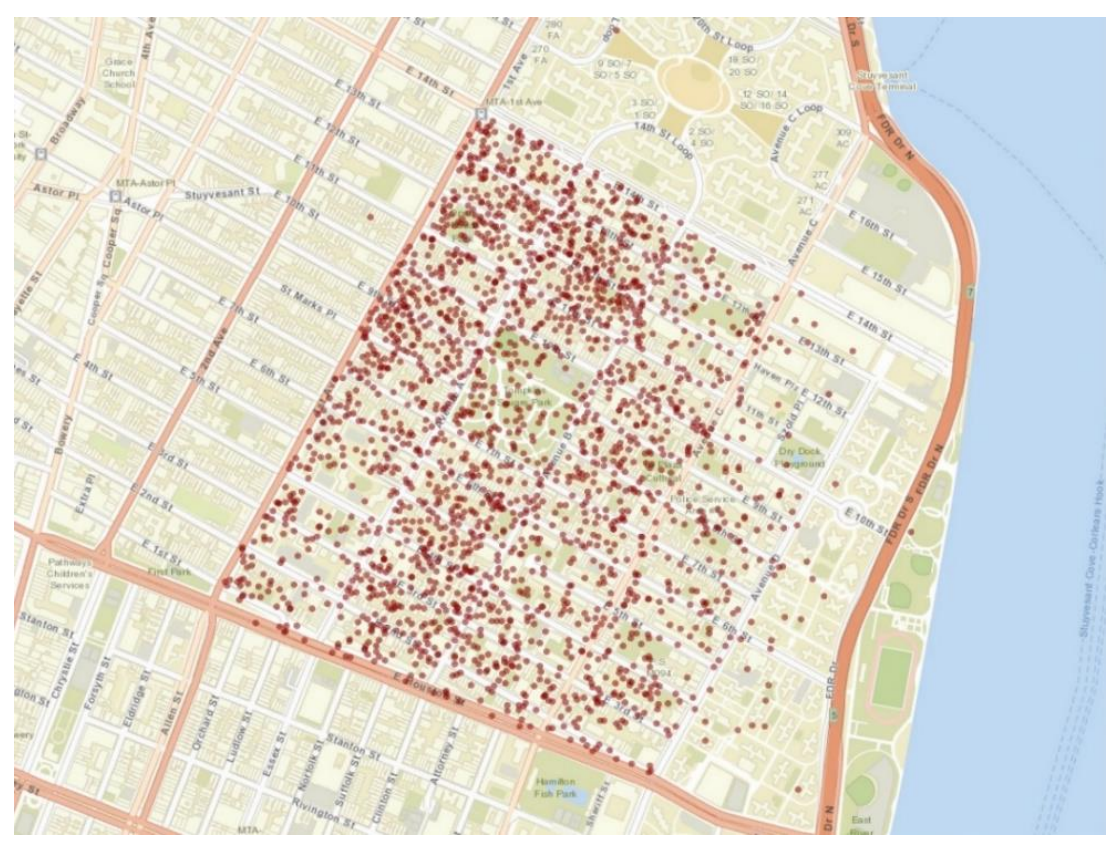

Figure 1: The Map of Data

\subsection{Binomial Logistic Model (Adding Consecutive Booking Status Variable) \\ 4.2.1 Model Building}

The binomial logistic model is usually used to study the influence of multiple independent variables on discrete binary dependent variables. It can analyze the probability that an individual with a certain characteristic makes a certain choice but not another. The dependent variable studied in this paper is whether the property owner will block the house. The blocking status (Status B) is recorded as "1", and the unblocking status (Status A\&R) is recorded as "0". Let $p_{i}$ be the probability that the landlord chooses to block the house, the expression of the binomial model for the blocking status is:

$p_{i}=\frac{e^{\left(\beta_{0}+\beta_{1} \cdot x_{1}+\cdots+\beta_{n} \cdot x_{n}\right)}}{1+e^{\left(\beta_{0}+\beta_{1} \cdot x_{1}+\cdots+\beta_{n} \cdot x_{n}\right)}}$

Among them, $\beta_{0}$ is a constant term that has nothing to do with various measurement factors, $\beta_{1}, \beta_{2}, \cdots \cdots, \beta_{n}$ are regression coefficients, which represent the contribution rate of the measurement index $x_{i}$ to the blocking probability $p_{i}$. The logit transformation of equation (4.1), as shown in the equation (4.2), produces a linear function of parameters $\beta_{1}, \beta_{2}, \cdots \cdots, \beta_{n}$. It can be seen that the binomial logistic regression model that fits the blocking status is converted into a fitted linear regression model. 


$$
Y=\ln \frac{p_{i}}{1-p_{i}}=\beta_{0}+\beta_{1} \cdot x_{1}+\cdots+\beta_{n} \cdot x_{n}
$$

Among them, $\beta_{1}$ represents the logarithmic change value of the ratio of the probability that the house becomes blocked when $x_{1}$ changes by one unit.

Variable Neighborhood, Week, Property Type and Listing Type are categorical variables, with the reference level being "East Village" for variable Neighborhood, "Friday" for variable Week, "Apartment" for variable Property Type and "Entire home/apt" for variable Listing Type. Other categories in each categorical variable are changed to dummy variables automatically. We want to explore the impact of these variables on landlord behavior. In total, there are 21 independent variables. 
Table 2: Variable Table I

\begin{tabular}{|c|c|c|}
\hline $\begin{array}{l}\text { Variable } \\
\text { Name }\end{array}$ & Variable Symbol & Variable Definitions \\
\hline Status & Status & 1=B Status, $0=A \& B$ Status \\
\hline Price & Price & Continuous Variable \\
\hline Bedrooms & Bedrooms & Continuous Variable \\
\hline $\begin{array}{l}\text { Consecutive } \\
\text { Booking }\end{array}$ & ConsecutiveBooking & Continuous Variable \\
\hline $\begin{array}{l}\text { Consecutive } \\
\text { A Status }\end{array}$ & ConsecutiveA & Continuous Variable \\
\hline $\begin{array}{l}\text { Consecutive } \\
\text { B Status }\end{array}$ & ConsecutiveB & Continuous Variable \\
\hline Property Type & PropertyType & $\begin{array}{c}\text { PropertyTypeBed\&amp; Breakfast } \\
=\{1=\text { Bed\&amp; Breakfast, } 0=\text { Apartment }\} \\
\text { PropertyTypeCabin }=\{1=\text { Cabin, } 0=\text { Apartment }\} \\
\text { PropertyTypeCondominium }=\{1=\text { Condominium, } \\
0=\text { Apartment }\} \\
\text { PropertyTypeEntire home/apt } \\
=\{1=\text { Entire home/apt, } 0=\text { Apartment }\} \\
\text { PropertyTypeHouse }=\{1=\text { House, } 0=\text { Apartment }\} \\
\text { PropertyTypeLoft }=\{1=\text { Loft, } 0=\text { Apartment }\} \\
\text { PropertyTypeNA }=\{1=\mathrm{NA}, 0=\text { Apartment }\} \\
\text { PropertyTypeTownhouse }=\{1=\text { Townhouse, } \\
0=\text { Apartment }\} \\
\text { PropertyTypeVilla }=\{1=\text { Villa, } 0=\text { Apartment }\}\end{array}$ \\
\hline Listing Type & ListingType & $\begin{array}{c}\text { ListingTypePrivate room }=\{1=\text { Private room, } \\
0=\text { Entire home } / \text { apt }\} \\
\text { ListingTypeShared room }=\{1=\text { Shared room, } \\
0=\text { Entire home/apt }\}\end{array}$ \\
\hline Neighborhood & Neighborhood & $\begin{array}{c}\text { NeighborhoodStuyvesantsant Town } \\
=\{1=\text { Stuyvesantsant Town, } 0=\text { East Village }\}\end{array}$ \\
\hline Week & Week & $\begin{aligned} \text { WeekMonday } & =\{1=\text { Monday, } 0=\text { Friday }\} \\
\text { WeekSaturday } & =\{1=\text { Saturday, } 0=\text { Friday }\} \\
\text { WeekSunday } & =\{1=\text { Sunday, } 0=\text { Friday }\} \\
\text { WeekThursday } & =\{1=\text { Thursday, } 0=\text { Friday }\} \\
\text { WeekTuesday } & =\{1=\text { Tuesday, } 0=\text { Friday }\} \\
\text { WeekWednesday } & =\{1=\text { Wednesday, } 0=\text { Friday }\}\end{aligned}$ \\
\hline
\end{tabular}


The logistic model :

$$
\begin{aligned}
\ln \frac{p_{i}}{1-p_{i}}=\beta_{0} & +\beta_{1} \times \text { Price } \\
& +\beta_{2} \times \text { Bedrooms } \\
& +\beta_{3} \times \text { ConsecutiveBooking } \\
& +\beta_{4} \times \text { PropertyTypeBed\&amp }+\beta_{5} \times \text { PropertyTypeCabin } \\
& +\beta_{6} \times \text { PropertyTypeCondominium } \\
& +\beta_{7} \times \text { PropertyTypeEntire }+\beta_{8} \times \text { PropertyTypeHouse } \\
& +\beta_{9} \times \text { PropertyTypeLoft }+\beta_{10} \times \text { PropertyTypeNA } \\
& +\beta_{11} \times \text { PropertyTypeTownhouse } \\
& +\beta_{12} \times \text { PropertyTypeVilla } \\
& +\beta_{13} \times \text { ListingTypePrivate room } \\
& +\beta_{14} \times \text { ListingTypeShared room } \\
& +\beta_{15} \times \text { NeighborhoodStuyvesantsant Town } \\
& +\beta_{16} \times \text { WeekMonday }+\beta_{17} \times \text { WeekSaturday } \\
& +\beta_{18} \times \text { WeekSunday }+\beta_{19} \times \text { WeekThursday } \\
& +\beta_{20} \times \text { WeekTuesday }+\beta_{21} \times \text { WeekWednesday }
\end{aligned}
$$

\subsubsection{Model Results}

Using $\mathrm{R}$ for regression, we get the coefficient estimates, standard errors, $\mathrm{z}$ statistics and corresponding $\mathrm{P}$ values of each variable. 
Table 3: Logistic Regression Model Results I

\begin{tabular}{|c|c|c|c|c|}
\hline Variable & $\begin{array}{c}\text { Coefficient } \\
\text { Estimates } \\
\end{array}$ & $\begin{array}{c}\text { Std. } \\
\text { Error }\end{array}$ & $Z$ value & $P$ value \\
\hline (Intercept) & $-0.361^{* * *}$ & 0.051 & -7.128 & 0.000 \\
\hline Price & $-0.002^{* * *}$ & 0.000 & -10.620 & 0.000 \\
\hline Bedrooms & $0.326^{* * *}$ & 0.024 & 13.558 & 0.000 \\
\hline Consecutive Booking & $-0.214^{* * *}$ & 0.012 & -17.889 & 0.000 \\
\hline $\begin{array}{c}\text { Property Type Bed \& amp; } \\
\text { Breakfast }\end{array}$ & 16.170 & 275.000 & 0.059 & 0.953 \\
\hline Property Type Cabin & -15.120 & 265.700 & -0.057 & 0.955 \\
\hline Property Type Condominium & $-1.393^{* * *}$ & 0.324 & -4.305 & 0.000 \\
\hline $\begin{array}{c}\text { Property Type Entire } \\
\text { home/apt }\end{array}$ & $2.256^{* * *}$ & 0.366 & 6.170 & 0.000 \\
\hline Property Type House & $-1.114^{* * *}$ & 0.141 & -7.925 & 0.000 \\
\hline Property Type Loft & $-3.032^{* * *}$ & 0.507 & -5.976 & 0.000 \\
\hline Property Type NA & -15.310 & 265.700 & -0.058 & 0.954 \\
\hline Property Type Town House & -14.480 & 129.400 & -0.112 & 0.911 \\
\hline Property Type Villa & $1.619^{* *}$ & 0.643 & 2.519 & 0.012 \\
\hline Listing Type Private room & $-0.409^{* * *}$ & 0.033 & -12.328 & 0.000 \\
\hline Listing Type Shared room & $-1.360^{* * *}$ & 0.129 & -10.532 & 0.000 \\
\hline $\begin{array}{c}\text { Neighborhood stuyvesant } \\
\text { Town }\end{array}$ & $-0.131^{* *}$ & 0.063 & -2.066 & 0.039 \\
\hline Week Monday & 0.054 & 0.053 & 1.015 & 0.310 \\
\hline Week Saturday & 0.036 & 0.054 & 0.680 & 0.500 \\
\hline Week Sunday & 0.085 & 0.053 & 1.602 & 0.109 \\
\hline Week Thursday & 0.071 & 0.051 & 1.413 & 0.158 \\
\hline Week Tuesday & 0.066 & 0.053 & 1.245 & 0.213 \\
\hline Week Wednesday & 0.049 & 0.050 & 0.977 & 0.329 \\
\hline
\end{tabular}

Chi-square : 255.619

Note: "*", "**", and "***" indicate the significance levels of $10 \%, 5 \%$, and $1 \%$ respectively. 


\subsubsection{Significance Test}

From the p-value above, it is obvious that 10 variables(Price, Bedrooms, Consecutive Booking, Property Type(including Condominium, Entire home/apt, House, Loft),Listing type(containing Private room and shared room)) have a highly significant impact on dependent variable Status at over 99\% confidence level, 2 variables (Proper type Villa and Neighborhood Stuyvesant Town) have relatively lower significant influence on Status at 95\% confidence level.

\subsubsection{Interpretation}

The correlation coefficient was analyzed by precise values

Coefficient of Price: $\exp (-1.885 \mathrm{e}-03)=0.998$, when the price increase 1 unit, the odds of blocking changes by a factor of 0.998 , when all other variables are held constant, that is, the odds of blocking the room decreases by a factor of $0.2 \%$ for every additional one dollar.

Coefficient of Bedroom: $\exp (3.264 \mathrm{e}-01)=1.383$, when the number of bedroom increase 1 unit, the odds of blocking changes by a factor of 1.383 , when all other variables are held constant, that is, the odds of blocking the room increases by a factor of 1.383 for every additional one bedroom.

Coefficient of Consecutive Booking: $\exp (-2.138 \mathrm{e}-01)=0.808$, when the number of consecutive booking days increase 1 unit, the odds of blocking changes by a factor of 0.808 , when all other variables are held constant, that is, the odds of blocking the room decreases by a factor of $19.2 \%$ for every additional one day. Coefficient of Condominium: $\exp (-1.393 \mathrm{e}+00)=0.248$, the odds of blocking the Condominium room changes by a factor of 0.248 than blocking an Apartment, when all other variables are held constant, that is, the odds of blocking the room decreases by $75.2 \%$ if it is a Condominium.

Coefficient of Entire home/apt: $\exp (2.256 \mathrm{e}+00)=9.545$, the odds of blocking the Entire home/apt changes by a factor of 9.545 than blocking an Apartment, when all other variables are held constant.

Coefficient of House: $\exp (-1.114 \mathrm{e}+00)=0.328$, the odds of blocking the Houseroom changes by a factor of 0.328 than blocking an Apartment, when all other variables are held constant, that is, the odds of blocking the room decreases by $67.2 \%$ if it is a House.

Coefficient of Loft: $\exp (-3.032 \mathrm{e}+00)=0.048$, the odds of blocking the Loft room changes by a factor of 0.048 than blocking an Apartment, when all other variables are held constant, that is, the odds of blocking the room decreases by $95.2 \%$ if it is a Loft.

Based on the odds calculated above, we can see that in general, the odds of blocking a Entire home/apt room is higher than on Apartment, which is also highly statistically significant. Among other significant dummy variables of property types, we can see that the odds of blocking a Condominium, a House and a Loft are all lower than blocking an Apartment, and a Loft is much less likely to be blocked. Coefficient of Listing Type - Private Room: $\exp (-4.093 \mathrm{e}-01)=0.664$, the odds of 
blocking a Private Room changes by a factor of 0.664 than blocking an Entire home/apt, when all other variables are held constant, that is, the odds of blocking a Private Room decreases by $33.6 \%$.

Coefficient of Listing Type - Shared Room: $\exp (-1.360 \mathrm{e}+00)=0.257$, the odds of blocking a Private Room changes by a factor of 0.257 than blocking an Entire home/apt, when all other variables are held constant, that is, the odds of blocking a Private Room decreases by $74.3 \%$.

Based on the odds computed above, we can see that the odds of blocking a Private Room and a Shared Room are both lower than blocking an Entire home/apt, and a Shared Room is much less likely to be blocked than a Private Room. 
4.3 Binomial Logistic Model (Adding Consecutive B Status Variable)

Table 4: Logistic Regression Model Results II

\begin{tabular}{|c|c|c|c|c|}
\hline Variable & $\begin{array}{l}\text { Coefficient } \\
\text { Estimates }\end{array}$ & Std. Error & $\mathrm{Z}$ value & $P$ value \\
\hline (Intercept) & $-2.039^{* * *}$ & 0.085 & -23.882 & 0.000 \\
\hline Price & $-0.002^{* * *}$ & 0.000 & -5.034 & 0.000 \\
\hline Bedrooms & $0.212^{* * *}$ & 0.038 & 5.535 & 0.000 \\
\hline Consecutive B & $1.094^{* * *}$ & 0.020 & 54.773 & 0.000 \\
\hline $\begin{array}{c}\text { Property Type Bed \& amp; } \\
\text { Breakfast }\end{array}$ & 11.700 & 61.250 & 0.191 & 0.849 \\
\hline Property Type Cabin & -11.420 & 97.450 & -0.117 & 0.907 \\
\hline Property Type Condominium & -0.281 & 0.368 & -0.764 & 0.445 \\
\hline Property Type Entire home/apt & $1.363^{* * *}$ & 0.504 & 2.704 & 0.007 \\
\hline Property Type House & $-1.291^{* * *}$ & 0.291 & -4.434 & 0.000 \\
\hline Property Type Loft & $-1.684^{* * *}$ & 0.543 & -3.013 & 0.002 \\
\hline Property Type NA & -11.570 & 97.450 & -0.119 & 0.905 \\
\hline Property Type Town House & -10.920 & 51.490 & -0.212 & 0.832 \\
\hline Property Type Villa & $2.441^{* * *}$ & 0.694 & 3.517 & 0.000 \\
\hline Listing Type Private room & $-0.385^{* * *}$ & 0.057 & -6.745 & 0.000 \\
\hline Listing Type Shared room & $-0.831^{* * *}$ & 0.195 & -4.255 & 0.000 \\
\hline Neighborhood stuyvesant Town & -0.169 & 0.113 & -1.502 & 0.133 \\
\hline Week Monday & $-0.212^{* *}$ & 0.093 & -2.276 & 0.023 \\
\hline Week Saturday & -0.085 & 0.089 & -0.950 & 0.342 \\
\hline Week Sunday & -0.114 & 0.091 & -1.248 & 0.212 \\
\hline Week Thursday & $0.263^{* * *}$ & 0.081 & 3.239 & 0.001 \\
\hline Week Tuesday & $-0.193^{* *}$ & 0.093 & -2.079 & 0.038 \\
\hline Week Wednesday & $0.416^{* * *}$ & 0.080 & 5.165 & 0.000 \\
\hline
\end{tabular}

Note: "*", "**", and "***" indicate the significance levels of $10 \%, 5 \%$, and $1 \%$ respectively. 
Coefficient of Consecutive B: $\exp (1.094 \mathrm{e}+00)=2.986$, when the number of Consecutive B days increase 1 unit, the odds of blocking changes by a factor of 2.986, when all other variables are held constant, that is, the odds of blocking the room increases by a factor of 2.986 for every additional one day.

\subsection{Binomial Logistic Model (Adding Consecutive A Status Variable)}

Table 5: Logistic Regression Model Results III

\begin{tabular}{|c|c|c|c|c|}
\hline Variable & $\begin{array}{c}\text { Coefficient } \\
\text { Estimates }\end{array}$ & Std. Error & $\mathrm{Z}$ value & $\mathrm{P}$ value \\
\hline (Intercept) & $0.720^{* * * *}$ & 0.066 & 10.913 & 0.000 \\
\hline Price & -0.0001 & 0.000 & -0.931 & 0.352 \\
\hline Bedrooms & $0.169^{* * *}$ & 0.033 & 5.109 & 0.000 \\
\hline Consecutive A & $-0.906^{* * *}$ & 0.020 & -44.773 & 0.000 \\
\hline $\begin{array}{c}\text { Property Type Bed \& amp; } \\
\text { Breakfast }\end{array}$ & 1.574 & 452.300 & 0.035 & 0.972 \\
\hline Property Type Cabin & -1.358 & 292.300 & -0.046 & 0.963 \\
\hline Property Type Condominium & $-0.966^{* *}$ & 0.391 & -2.474 & 0.013 \\
\hline Property Type Entire home/apt & $0.802^{* *}$ & 0.368 & 2.177 & 0.030 \\
\hline Property Type House & $-1.330^{* * *}$ & 0.170 & -7.809 & 0.000 \\
\hline Property Type Loft & $-2.277^{* * *}$ & 0.545 & -4.176 & 0.000 \\
\hline Property Type NA & -0.136 & 292.300 & -0.047 & 0.963 \\
\hline Property Type Town House & -13.84 & 170.800 & -0.081 & 0.935 \\
\hline Property Type Villa & 0.2474 & 0.702 & 0.353 & 0.724 \\
\hline Listing Type Private room & $-0.121^{* * * *}$ & 0.044 & -2.726 & 0.006 \\
\hline Listing Type Shared room & $-1.061^{* * *}$ & 0.161 & -6.599 & 0.000 \\
\hline Neighborhood stuyvesant Town & $0.438^{* * * *}$ & 0.099 & 4.414 & 0.000 \\
\hline Week Monday & $0.239^{* * *}$ & 0.074 & 3.231 & 0.001 \\
\hline Week Saturday & $0.161^{* * *}$ & 0.073 & 2.212 & 0.027 \\
\hline Week Sunday & $0.224^{* * *}$ & 0.074 & 3.044 & 0.002 \\
\hline Week Thursday & -0.045 & 0.066 & -0.671 & 0.502 \\
\hline Week Tuesday & $0.283^{* * *}$ & 0.074 & 3.797 & 0.000 \\
\hline Week Wednesday & $-0.245^{* * *}$ & 0.062 & -3.696 & 0.000 \\
\hline
\end{tabular}

Note: "*", "**", and "***" indicate the significance levels of $10 \%, 5 \%$, and $1 \%$ respectively. 
The price coefficient is not significant.

Coefficient of Consecutive A: $\exp (-9.064 \mathrm{e}-01)=0.404$, when the number of consecutive booking days increase 1 unit, the odds of blocking changes by a factor of 0.404 , when all other variables are held constant, that is, the odds of blocking the room decreases by a factor of $59.6 \%$ for every additional one day.

\section{Optimization Analysis}

As can be seen from the previous chapter, price has a significant impact on landlord behavior. As the most easily changed attribute, price has an important influence on the matching of supply and demand. In order for the platform to recommend suitable prices to listed owners, we will build an optimization model based on the original model to study the impact of price on housing occupancy rate in order to calculate the opportunity cost and obtain the utility of the property owner to determine the price that can maximize the listing revenue.

\subsection{Quasibinomial Regression Model}

\subsubsection{Model Building}

The independent variable is the same as the original model, and the dependent variable is occupancy rate.

Variable Neighborhood, Week, Property Type and Listing Type are categorical variables, with the reference level being "East Village" for variable Neighborhood, "A" for variable Satus, "Apartment" for variable Property Type and "Entire home/apt" for variable Listing Type. Other categories in each categorical variable are changed to dummy variables automatically. 
Table 6: Variable Table II

\begin{tabular}{|c|c|c|}
\hline $\begin{array}{l}\text { Variable } \\
\text { Name }\end{array}$ & Variable Symbol & Variable Definitions \\
\hline $\begin{array}{l}\text { Occupancy } \\
\text { Rate }\end{array}$ & OccupancyRate & Continuous Variable \\
\hline Price & Price & Continuous Variable \\
\hline Bedrooms & Bedrooms & Continuous Variable \\
\hline Consecutive $\mathrm{R}$ & ConsecutiveBooking & Continuous Variable \\
\hline Status & Status & $\begin{array}{l}\text { StatusB }=\{1=B, 0=A\} \\
\text { StatusR }=\{1=R, 0=A\}\end{array}$ \\
\hline Property Type & PropertyType & $\begin{array}{c}\text { PropertyTypeBed\&amp; Breakfast } \\
=\{1=\text { Bed\&amp; Breakfast, } 0=\text { Apartment }\} \\
\text { PropertyTypeCabin }=\{1=\text { Cabin, } 0=\text { Apartment }\} \\
\text { PropertyTypeCondominium }=\{1=\text { Condominium, } \\
0=\text { Apartment }\} \\
\text { PropertyTypeEntire home/apt } \\
=\{1=\text { Entire home/apt, } 0=\text { Apartment }\} \\
\text { PropertyTypeHouse }=\{1=\text { House, } 0=\text { Apartment }\} \\
\text { PropertyTypeLoft }=\{1=\text { Loft, } 0=\text { Apartment }\} \\
\text { PropertyTypeNA }=\{1=\mathrm{NA}, 0=\text { Apartment }\} \\
\text { PropertyTypeTownhouse }=\{1=\text { Townhouse, } \\
0=\text { Apartment }\} \\
\text { PropertyTypeVilla }=\{1=\text { Villa, } 0=\text { Apartment }\}\end{array}$ \\
\hline Listing Type & ListingType & $\begin{array}{c}\text { ListingTypePrivate room }=\{1=\text { Private room, } \\
0=\text { Entire home } / \text { apt }\} \\
\text { ListingTypeShared room }=\{1=\text { Shared room, } \\
0=\text { Entire home/apt }\}\end{array}$ \\
\hline Neighborhood & Neighborhood & $\begin{aligned} & \text { NeighborhoodStuyvesantsant Town } \\
= & \{1=\text { Stuyvesantsant Town, } 0=\text { East Village }\}\end{aligned}$ \\
\hline
\end{tabular}


The model:

$$
\begin{aligned}
\ln Y=\beta_{0}+\beta_{1} & \times \text { Price } \\
& +\beta_{2} \times \text { Bedrooms } \\
& +\beta_{3} \times \text { Consecutive } R \\
& +\beta_{4} \times \text { PropertyTypeBed\&amp }+\beta_{5} \times \text { PropertyTypeCabin } \\
& +\beta_{6} \times \text { PropertyTypeCondominium } \\
& +\beta_{7} \times \text { PropertyTypeEntire }+\beta_{8} \times \text { PropertyTypeHouse } \\
& +\beta_{9} \times \text { PropertyTypeLoft }+\beta_{10} \times \text { PropertyTypeNA } \\
& +\beta_{11} \times \text { PropertyTypeTownhouse } \\
& +\beta_{12} \times \text { PropertyTypeVilla } \\
& +\beta_{13} \times \text { ListingTypePrivate room } \\
& +\beta_{14} \times \text { ListingTypeShared room } \\
& +\beta_{15} \times \text { NeighborhoodStuyvesantsant Town } \\
& +\beta_{16} \times \text { StatusB }+\beta_{17} \times \text { Status } R
\end{aligned}
$$




\subsubsection{Model Results}

Table 7: Quasibinomial Regression Model Results

\begin{tabular}{|c|c|c|c|c|}
\hline Variable & $\begin{array}{l}\text { Coefficient } \\
\text { Estimates }\end{array}$ & Std. Error & T value & $P$ value \\
\hline (Intercept) & $0.606^{* * *}$ & 0.017 & 35.576 & 0.000 \\
\hline Price & $-0.001^{* * *}$ & 0.000 & -11.795 & 0.000 \\
\hline Bedrooms & $0.042^{* * *}$ & 0.014 & 3.648 & 0.000 \\
\hline Consecutive $\mathrm{R}$ & $0.024^{* * *}$ & 0.003 & 7.122 & 0.000 \\
\hline Status B & $0.082^{* * * *}$ & 0.015 & 5.616 & 0.000 \\
\hline Status R & 0.020 & 0.032 & 0.637 & 0.000 \\
\hline $\begin{array}{c}\text { Property Type Bed \& amp; } \\
\text { Breakfast }\end{array}$ & $2.258^{* * * *}$ & 0.405 & 5.584 & 0.000 \\
\hline Property Type Cabin & $-2.088^{* * * *}$ & 0.253 & -8.246 & 0.000 \\
\hline Property Type Condominium & -0.165 & 0.110 & -1.510 & 0.131 \\
\hline Property Type Entire home/apt & 0.002 & 0.138 & -0.014 & 0.989 \\
\hline Property Type House & $0.404^{* * *}$ & 0.057 & 7.078 & 0.000 \\
\hline Property Type Loft & $-0.191^{* *}$ & 0.085 & -2.250 & 0.024 \\
\hline Property Type NA & $2.878^{* * * *}$ & 0.530 & 5.427 & 0.000 \\
\hline Property Type Town House & 0.179 & 0.125 & 1.433 & 0.151 \\
\hline Property Type Villa & $0.648^{*}$ & 0.355 & 1.828 & 0.067 \\
\hline Listing Type Private room & $-0.163^{* * * *}$ & 0.016 & -10.355 & 0.000 \\
\hline Listing Type Shared room & $-0.622^{* * *}$ & 0.050 & -12.494 & 0.000 \\
\hline Neighborhood stuyvesant Town & $-0.116^{* * *}$ & 0.031 & -3.760 & 0.000 \\
\hline
\end{tabular}

Note: "*", "**", and "***" indicate the significance levels of $10 \%, 5 \%$, and $1 \%$ respectively.

\subsubsection{Significance Test}

From the p-value above, it is obvious that 11 variables(Price, Bedrooms, Consecutive R, Status(A; B), Property Type(including Bed \& amp; Breakfast, Cabin, House),Listing type(containing Private room and shared room)) have a highly significant impact on dependent variable Occupancy Rate at over $99 \%$ confidence level, 1 variables (Proper type Loft) have relatively lower significant influence on Status at 95\% confidence level, 1 variables (Proper type Villa) have relatively lower significant influence on Status at $90 \%$ confidence level. 


\subsubsection{Interpretation}

The correlation coefficient was analyzed by precise values

Coefficient of Price: $\exp (-8.017 \mathrm{e}-04)=0.999$, when the price increase one unit, the odds of blocking changes by a factor of 0.999 , when all other variables are held constant, that is, the odds of blocking the room decreases by a factor of $0.001 \%$ for every additional one dollar.

\subsection{Data Driven Optimization}

For data optimization research, we need to calculate the utility level of the property owner. For this we need the listing price of the property and the probability of renting, and get the opportunity cost.

Airbnb can match users with landlords. Due to the user experience of the accommodation platform, it is more likely to form a monopoly. Large-scale Airbnb has grown in many markets. Even if competitors have strong capital and increase subsidies, it is difficult for them to enter the industry ( $\mathrm{Li}, 2019)$. At present, in most European countries, Airbnb has formed a monopoly, considering that its focus is no longer on competitors and price wars. So in this case, we assumed that there was only one monopolistic platform in the market when building the model.

$U_{S}$ is the utility. And because it is a monopolistic platform, all consumers and suppliers can only choose this platform for transactions, and they can only match the only object on the platform. We assume that the probability of successful matching is $\Omega$, and we know $\Omega \in[0,1]$. Meanwhile, we use $P$ to represent the rent of property and $C$ to represent the cost when property owners decide to block their houses. Opportunity cost refers to the listing price that the owner loses under the probability of listing being booked when he decides to block house on a specific date.

We establish the utility function of the property owners as follows

$U_{s}=P-C \times \Omega$

Opportunity Cost $=C \times \Omega$

To calculate the utility, we select the rental price of every property rented and remove houses that were not open and rented during the month to calculate average rent. Opportunity cost is the average price of properties of the same type and with the same number of bedrooms. The probability of successful matching is the coefficient of price $(\Omega=0.999)$. 


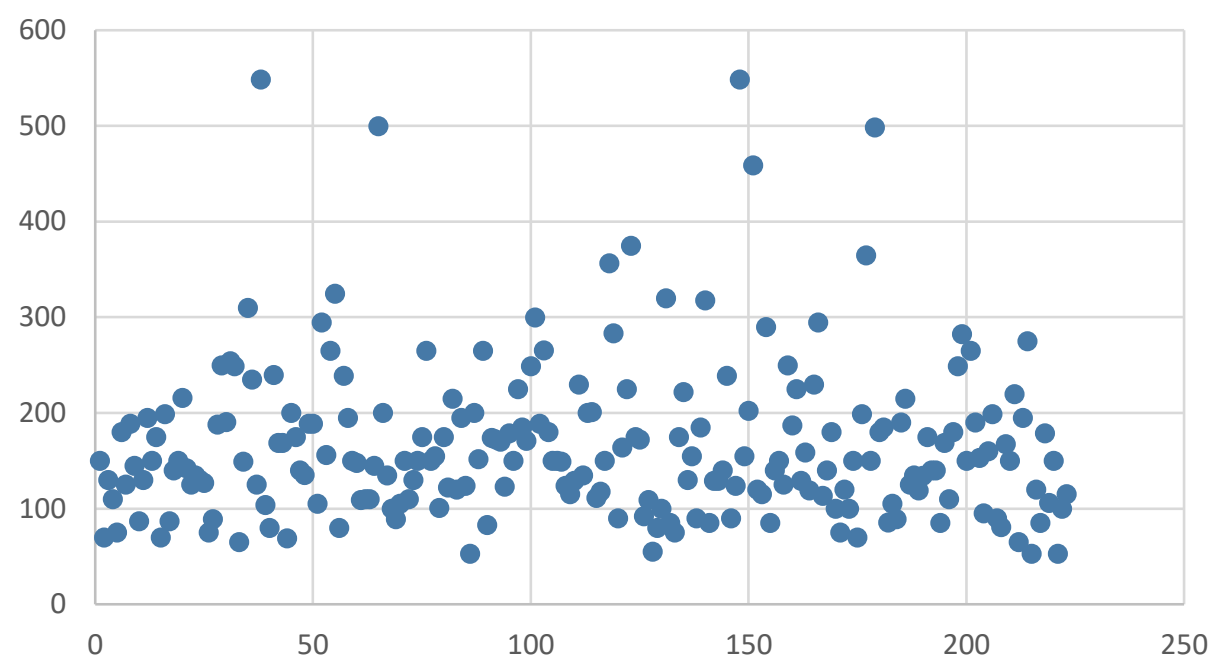

Figure 2: The Distribution of Opportunity Cost

The average of the opportunity cost is 166.155 . We can know the utility of house supplier (Figure 3).

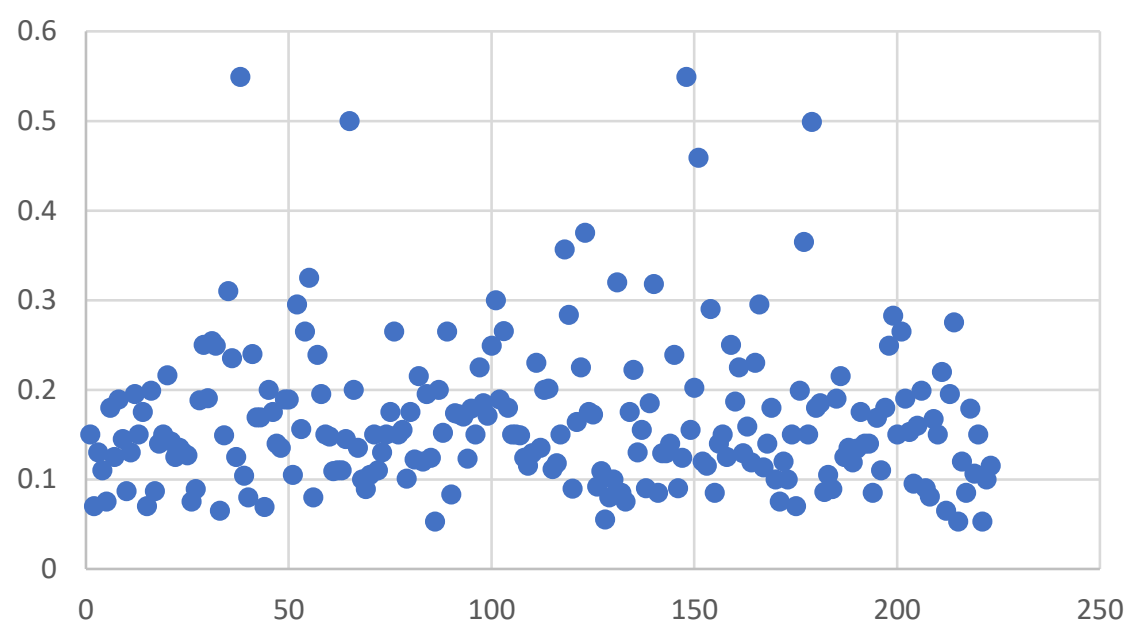

Figure 3: The Distribution of Utility

Next, we're going to calculate the profits of property owners as follows.

Profit $=P \times$ Occupancy Rate 


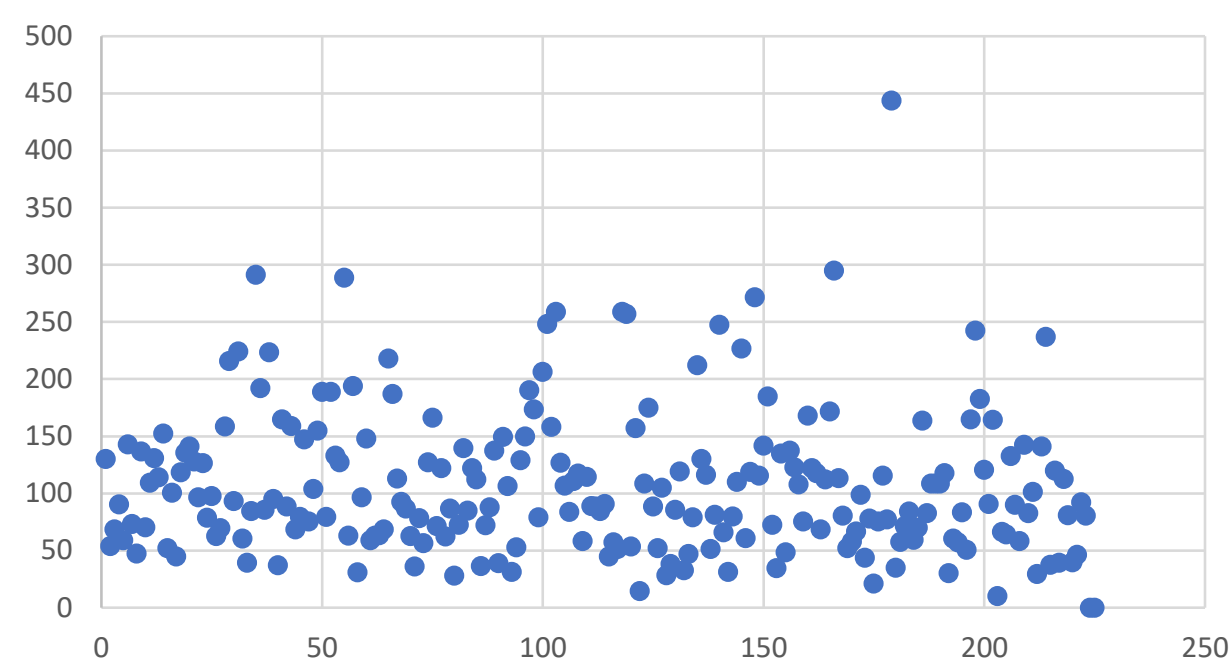

Figure 4: The Distribution of Profit

Table 8: Descriptive Statistics of Variables II

\begin{tabular}{|c|c|c|c|c|}
\hline Variable & Mean & $\begin{array}{c}\text { Standard } \\
\text { Deviation }\end{array}$ & Max & Min \\
\hline Utility & 0.166 & 0.083 & 0.549 & 0.053 \\
\hline Opportunity Cost & 166.155 & 82.438 & 548.451 & 0.000 \\
\hline Profit & 107.145 & 63.111 & 443.611 & 52.947 \\
\hline
\end{tabular}

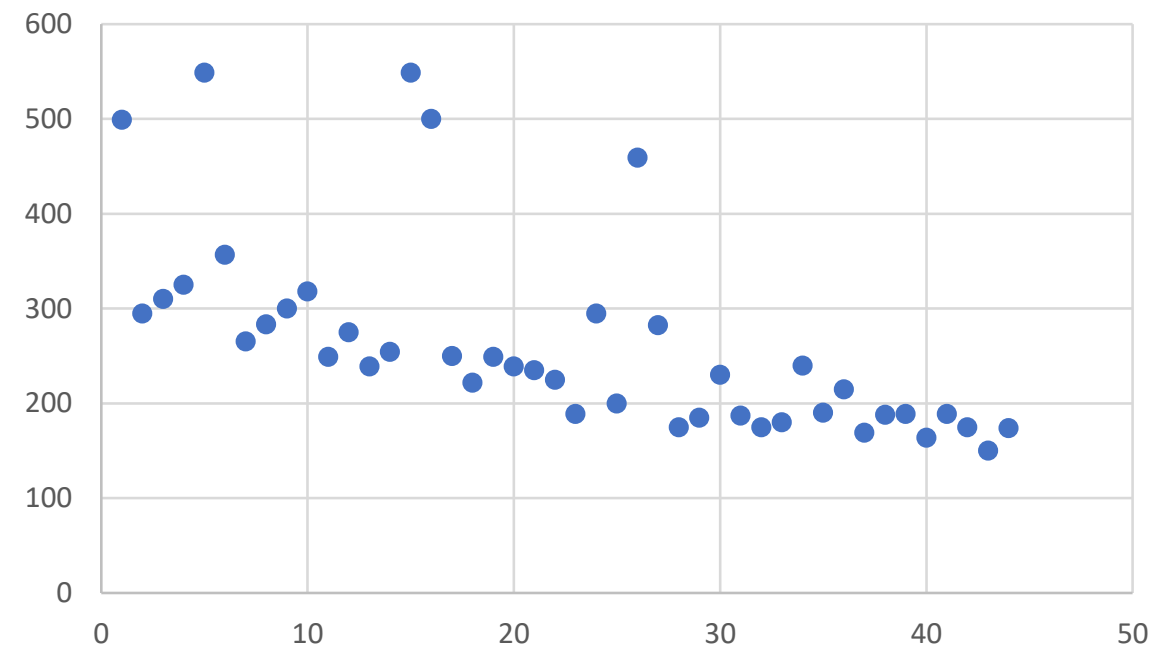

Figure 5: Price Distribution of Top 20\% Profit 
In order to find the best price, we select the housing price corresponding to the top $20 \%$ profit and calculate the $95 \%$ confidence interval of the mean $(231.98,294.76)$. We believe that this range represents the best and reasonable range of pricing and the landlord can get the best profit.

\section{The Possibility of Extended Research}

In the previous two chapters, we analyzed the factors that affect the behavior of property owners to block houses and the utility of their actions. We know that Airbnb has no direct pricing power, but can only give the landlord a guide price. In traditional pricing strategies, such as hotels and retail, it has all pricing power and can change the price at any time, so they have time to test different pricing strategies, as well as the market's response, can be optimized. All Airbnb can do is to provide price suggestions and subsidies such as coupons, or to reward or punish landlords and customers based on their performance.

In fact, for each room of the day, there is an optimal price that maximizes the utility for both the landlord and the consumer. However, the landlord's valuation of a room is based more on experience and perception, as well as comparing prices of other properties. Inevitably, prices are often much higher or lower than they should be, which severely reduces the success of deal matching. The profit of the platform is closely related to the success of the trade match, so pricing at the most profitable price can increase the total profitability of the platform without the need to change the transaction fee policy. However, the need for a universal pricing recommendation is difficult, and this paper will analyze the reasons for this and give some directions for later researchers to continue to explore the pricing mechanism.

\subsection{More Data to Analyze}

In this paper, we selected relevant data in a specific area of New York during one month, and obtained the approximate range for maximizing revenue. However, if it is extended to a large area or in different countries, the conclusion may not be applicable due to differences in holidays, culture, and natural environment. Therefore, to conduct more extensive price guidance, more data research from various regions is needed.

Later researchers can collect and analyze data for a longer period of time, add timevarying parameter $t$ to the model, and study the impact of peak and low rental demand on pricing.

\subsection{Complex Demand Function}

In the past, exploratory research on the optimal price generally focused on products of the same quality, and obtained a series of sample data through surveys to track how demand changes with price changes, thereby deriving a demand curve that regards demand as a function of price.

But in Airbnb, products are no longer homogeneous. To be precise, almost no product in Airbnb is homogeneous. Therefore, its demand is actually affected by 
price, time, and housing quality. In addition, the landlord's score and rank of the list will also affect the impact on each individual supplier. Even if we only consider the same type of house, in the same block and the same size, as long as the demand is large enough, a landlord with a better historical evaluation has the right to set a higher price without worrying about the price increase and the punishment due to the decrease of booking probability. Product differentiation makes the measurement of Airbnb's demand function very complicated.

Researchers should add commodity differentiation parameter $u$ to the demand function to solve the problem of various types of property.

\subsection{Price Acceptance Problem}

Airbnb's guide price (or price recommendation) can only be partially accepted by the landlord, and from a psychological point of view, the landlord who can get the reservation some time ago will usually set a price slightly higher than the recommended price to take more profit (but may actually lose more). On the contrary, some landlords will think that other landlords will set the price according to the recommended price, so they will let their price be lower than the recommended price in an attempt to attract more consumers.

In addition, Airbnb's recommended price may be higher or lower than the maximum or minimum acceptable value set by the landlord (usually lower than the psychological minimum). For example, some landlords often set a very high minimum acceptable price, which leads to the true price is often the lowest value (rather than the true optimal price).

\section{Conclusion}

As a sharing platform for short-term rentals, Airbnb is not a price setter. Landlords need to set their own prices, and make changes to the blocking and available status of the house. And the housing supplier will consider the cost of blocking the housing and set the price they think is appropriate according to the various characteristics of the housing.

We mainly set out to affect the factors that affect the landlord's blockade and the best benefits that can be obtained from renting the house. Finally, we came to the following conclusion

Regarding the blockade of houses, 10 factors (Price, Bedrooms, Consecutive Booking, Property Type (including Condominium, Entire home/apt, House, Loft), Listing type (containing Private room and shared room)) have a highly significant impact. Among them, higher prices and longer consecutive bookings will reduce the probability of blockade, because the landlord will get more revenue. The increase in the number of bedrooms will increase the probability of house blockade, which may be because the house needs more time to maintain. Different types of properties have different impacts on blockade houses. Condominium, House and Loft have a lower blockade probability than Apartment, while Entire Home is the opposite. Both Private and Shared room have lower blockade probability than the 
Entire room. In addition, the landlord in Stuyvesant Town has a lower probability to block the house than in East Village.

Through calculation, the utility and profit obtained by the landlord can be seen to conform to the normal distribution. The average of the best profit is $\$ 107.145$. We take this as the best profit and conclude that the best range of property rental pricing in this area is $(231.98,294.76)$.

Our advice to Airbnb is that the platform should try its best to improve the success rate of transaction matching, which is the most important issue for Airbnb and even all sharing platforms. It can be seen from the model that the price has a significant impact on the landlord's behavior of blocking houses. As the most easily changed housing property, the price needs to be reasonably determined, so that it is easier to improve the utility level. In addition, the degree of house differentiation and time change parameters are also key considerations for Airbnb.

In addition, in order to better improve the success rate of transaction matching and integrate a complete set of pricing system, this paper also provides some directions for subsequent research. This problem is very complicated. At present, the official method is machine learning. We have also put forward some models that can be used to help the official test the reasonableness and effectiveness of the suggested prices in different regions and times. We hope that these models can help Airbnb price better.

Research has shown that factors such as price and property type will significantly affect the supply of shared products, which in turn affects the full utilization of idle resources and platform benefits. Reasonable price adjustments are of great value not only for the shared accommodation platform Airbnb, but also for the survival and development of other similar sharing economy platforms.

\section{ACKNOWLEDGEMENTS.}

The author would like to thank Dr. W. Zhu in IESE and Dr. Erikson S. Yan in UCLA for research assistance throughout this project. Un Leong in UCLA provided invaluable econometric technique. 


\section{References}

[1] Edelman, Benjamin G. and Luca, Michael, Digital Discrimination: The Case of Airbnb.com (January 10, 2014). Harvard Business School NOM Unit Working Paper No. 14-054, Available at SSRN:

https://ssrn.com/abstract=2377353 or http://dx.doi.org/10.2139/ssrn.2377353

[2] Fraiberger, Samuel P. and Sundararajan, Arun, Peer-to-Peer Rental Markets in the Sharing Economy (September 2017). NYU Stern School of Business Research Paper (First version March 2015; current version September 2017), Available at SSRN: https://ssrn.com/abstract $=2574337$ or http://dx.doi.org/10.2139/ssrn.2574337

[3] Chiara Farronato, Andrey Fradkin . The Welfare Effects of Peer Entry in the Accommodation Market: The Case of Airbnb(2018).NBER Working Papers 24361, National Bureau of Economic Research, Inc.

[4] Zervas, Georgios and Proserpio, Davide and Byers, John, The Rise of the Sharing Economy: Estimating the Impact of Airbnb on the Hotel Industry (Nov 18, 2016). Boston U. School of Management Research Paper No.2013-16, Available at SSRN: https://ssrn.com/abstract $=2366898$ or http://dx.doi.org/10.2139/ssrn.2366898

[5] Zervas, Georgios and Proserpio, Davide and Byers, John, The Rise of the Sharing Economy: Estimating the Impact of Airbnb on the Hotel Industry (Nov 18, 2016). Boston U. School of Management Research Paper No. 2013-16, Available at SSRN: https://ssrn.com/abstract $=2366898$ or http://dx.doi.org/10.2139/ssrn.2366898

[6] Yang Li. Research on Airbnb's Pricing Strategy[D]. Beijing Foreign Studies University,2019.Journal of Applied Medical Sciences (2020). http://www.scienpress.com/journal_focus.asp?Main_I 